\title{
Erratum to: Decreased urinary calbindin 1 levels in proteinuric rats and humans with distal nephron segment injuries
}

\author{
Tomoko Iida $\cdot$ Hidehiko Fujinaka $\cdot$ Bo Xu $\cdot$ Ying Zhang $\cdot$ Sameh Magdeldin • \\ Masaaki Nameta $\cdot$ Zan Liu $\cdot$ Yutaka Yoshida $\cdot$ Eishin Yaoita • \\ Shuichi Tomizawa $\cdot$ Akihiko Saito $\cdot$ Tadashi Yamamoto
}

Published online: 6 August 2013

(C) Japanese Society of Nephrology 2013

\section{Erratum to: Clin Exp Nephrol}

DOI 10.1007/s10157-013-0835-3

One of the affiliations of the co-author Sameh Magdeldin was omitted in the original publication of this article. That affiliation is shown below.

The online version of the original article can be found under doi:10.1007/s10157-013-0835-3.

T. Iida $\cdot$ H. Fujinaka $(\bowtie) \cdot S$. Tomizawa Institute for Clinical Research, Niigata National Hospital, 3-52 Akasaka-cho, Kashiwazaki 945-8585, Japan

e-mail: dext007@hotmail.com

T. Iida $\cdot$ H. Fujinaka $\cdot$ B. Xu $\cdot$ Y. Zhang $\cdot$ S. Magdeldin $\cdot$ M. Nameta - Z. Liu · Y. Yoshida - E. Yaoita - T. Yamamoto Department of Structural Pathology, Institute of Nephrology, Niigata University Graduate School of Medical and Dental Sciences, 1-757 Asahimachi-dori, Niigata 951-8510, Japan

T. Iida $\cdot$ A. Saito

Department of Pediatrics, Niigata University Medical and Dental Hospital, 1-757 Asahimachi-dori, Niigata 951-8510, Japan

\section{S. Magdeldin}

Department of Physiology, Faculty of Veterinary Medicine,

Suez Canal University, Ismailia 41522, Egypt 